\title{
Platelet-leukocyte activation and modulation of adhesion receptors in pediatric patients with congenital heart disease undergoing cardiopulmonary bypass
}

Cardiopulmonary bypass has been shown in adults to activate platelets and leukocytes, lead to the formation of circulating platelet-leukocyte conjugates, and alter adhesive receptors on both cell types. Pediatric patients with congenital heart disease undergoing cardiopulmonary bypass, however, have not been extensively studied and may represent a group at particular clinical risk for bleeding and pulmonary dysfunction. We studied 13 patients with congenital heart disease undergoing operations necessitating bypass, 7 with cyanotic and 6 with noncyanotic congenital heart disease. We determined that (1) the surface density of platelet glycoprotein Ib was significantly lower at baseline and throughout bypass in patients with cyanotic heart disease than in noncyanotic patients; (2) platelet glycoprotein Ib in both cyanotic and noncyanotic congenital heart disease decreased significantly during bypass, with a nadir of $75 \%$ of baseline values; (3) platelets were activated to a high degree, comparable with that seen in adults; (4) mean circulating monocyte-platelet conjugates rose significantly during bypass, increasing from $36 \%$ to $66 \%$ by the end of bypass, whereas neutrophil-platelet conjugates and lymphocyte-platelet conjugates declined; and (5) both monocytes and neutrophils were activated by cardiopulmonary bypass, as assessed by increased surface expression of CD11b and, in the case of monocytes, CD11b expression continued to increase even after termination of bypass. Patients with cyanotic and noncyanotic heart disease did not differ with respect to platelet or leukocyte activation or the formation of platelet-leukocyte conjugates. We conclude that in children with congenital heart disease cardiopulmonary bypass causes loss of platelet adhesion receptors, activation of platelets, formation of platelet-leukocyte conjugates, and leukocyte activation. Cyanotic and noncyanotic patients are qualitatively similarly affected; however, cyanotic patients demonstrate a baseline deficit in the platelet adhesion receptor glycoprotein Ib. These cellular changes may contribute to both the hemostatic and inflammatory complications associated with cardiopulmonary bypass. (J THORAC CARDIOVASC SURG 1994;107:280-8)

Christine S. Rinder, MD, ${ }^{\mathrm{a}}$ Dorothy Gaal, MD, ${ }^{\mathrm{a}}$ Laura A. Student, BS, ${ }^{\mathrm{b}}$ and

Brian R. Smith, MD, ${ }^{\mathrm{b}}$ New Haven, Conn.

From the Departments of Anesthesiology and Laboratory Medicine, Yale University School of Medicine, New Haven, Conn.

Supported by a grant-in-aid from the American Heart Association, Connecticut Affiliate; National Institutes of Health (HL 47193); and the American Association of Blood Banks. Dr. Smith is a Scholar of the Leukemia Society of America.

Received for publication Dec. 8, 1992.

Accepted for publication March 30, 1993.

Address for reprints: Christine S. Rinder, MD, Department of Anesthesiology, Yale University School of Medicine, P.O. Box 3333, 333 Cedar St., New Haven, CT 06510.

Copyright $\odot 1994$ by Mosby-Year Book, Inc.

$0022-5223 / 94 \$ 1.00+.10 \quad \mathbf{1 2} / \mathbf{1} / \mathbf{4 8 8 1 1}$
$\mathrm{S}$ Structural and functional changes in circulating cells occurring in the adult population during cardiopulmonary bypass (CPB) have been described by us and others. Platelets are activated, resulting in release of $\alpha$-granule contents and expression of a neoantigen, P-selectin (CD62, GMP-140, PADGEM), on the surface of the activated platelets. ${ }^{1-3}$ In addition, surface expression of the major platelet von Willebrand factor receptor, glycoprotein (GP) Ib, and the fibrinogen receptor GPIIb/IIIa are both decreased during $\mathrm{CPB}$, although other platelet adhesive receptors such as GPIV remain unchanged. ${ }^{4-6}$ Leukocyte alterations during CPB include release of 
neutrophil elastase ${ }^{7}$ and expression of the adhesion receptor CD1 lb on the surface of monocytes and neutrophils (PMN). ${ }^{8}$ In vitro studies have demonstrated that the appearance of P-selectin on the surface of activated platelets mediates binding to monocytes and $\mathrm{PMN},{ }^{9}$ but not to the majority of lymphocytes. ${ }^{10-12} \mathrm{We}$ have previously shown that in temporal parallel to platelet activation during CPB the number of circulating monocytes and PMN with bound platelets increases significantly. ${ }^{8}$ Although the role of this in vivo platelet-leukocyte adhesion is not certain, preliminary work suggests that it may modulate the proinflammatory and prothrombotic effects of PMN and monocytes, ${ }^{13,14}$ and thus contribute to the pathophysiologic effects of $\mathrm{CPB}$.

Children with congenital heart disease (CHD) exhibit a host of unique physiologic characteristics that may place them at particular risk for the hemorrhagic and inflammatory complications associated with CPB. Platelet dysfunction, thrombocytopenia, disseminated intravascular coagulation, and decreases in coagulation factors are prevalent in pediatric patients with either noncyanotic or cyanotic CHD. ${ }^{15-17}$ This is especially prominent in the cyanotic population. ${ }^{18,19}$ In addition, the relatively large volume of the CPB circuit as compared with the patient's intravascular volume and the often high pump flow rates used may increase the degree of cellular injury associated with pediatric CPB.

Flow cytometry techniques allow the examination of large numbers of individual cells from small amounts of whole blood fixed immediately after blood drawing, permitting the detection of changes in surface adhesive proteins of platelets and leukocytes "frozen in time." We have used these techniques to study the changes in platelets and leukocytes of cyanotic and noncyanotic children with CHD undergoing CPB.

\section{Materials and methods}

Antibodies. All monoclonal antibodies (MoAb) were used as purified whole immunoglobulin G. All experiments included irrelevant isotype-specific mouse $\mathrm{MoAb}$ as negative controls. The monoclonal antibody $1 E 3^{20}$ is specific for P-selectin. $\mathrm{P} 2^{21}$ and $\mathrm{SZ2}^{22}$ (AMAC, Inc., Westbrook, Maine) recognize GPIIb/IIIa and GPIb, respectively. Anti-CD45 (HLE, BectonDickinson Immunocytometry Systems, San Jose, Calif.) recognizes a CD45 isoform present on PMN, monocytes, and lymphocytes but neither erythroid cells nor platelets. ${ }^{23}$ The MoAb D $12^{24}$ (Leu 15; Becton-Dickinson) recognizes CD1 Ib on monocytes and PMN.

Patient studies. After institutional approval by the Human Investigation Committee of the Yale University School of Medicine was obtained, 13 consecutive patients with CHD undergoing elective operations necessitating $\mathrm{CPB}$ were studied. They were divided into a cyanotic group $(n=7)$ and a noncyanotic group $(n=6)$ with cyanosis defined as a preoperative room air oxygen saturation of $85 \%$ or less. All patients underwent $\mathrm{CPB}$ with a Cobe VPCML membrane oxygenator (Cobe
Laboratories, Lakewood, Fla.) at comparable flow rates. Whole blood samples $(200 \mu \mathrm{l})$ were taken from the radial artery catheter and immediately fixed in $1 \%$ paraformaldehyde. Samples were taken at the following time points: before start of operation, after systemic heparinization before bypass, 10 minutes after start of bypass, at termination of bypass (before protamine administration), and 1 to 2 hours after bypass. Patient samples were studied for (1) platelet surface density of GPIb; (2) platelet activation (P-selectin expression); (3) leukocyte surface expression of CD1 lb; and (4) percentage of leukocyte-platelet conjugates.

Fluorescence labeling. All whole blood samples were fixed in paraformaldehyde for 60 minutes at $4^{\circ} \mathrm{C}$, then washed three times in Tyrode's-HEPES buffer (HEPES $5 \mathrm{mmol} / \mathrm{L}, \mathrm{NaCl}$ $140 \mathrm{mmol} / \mathrm{L}, \mathrm{KCl} 2.7 \mathrm{mmol} / \mathrm{L}$, dextrose $5.5 \mathrm{mmol} / \mathrm{L}$, $\mathrm{NaH}_{2} \mathrm{PO}_{4} 0.42 \mathrm{mmol} / \mathrm{L}$, and $\mathrm{NaHCO}_{3} 12 \mathrm{mmol} / \mathrm{L}, \mathrm{pH} 7.4$ ) and divided into three aliquots for study: one for platelet receptors, one for leukocyte surface CD11b, and one labeled for leukocyte-platelet conjugates.

For determination of the surface density of GPIb, $100 \mu \mathrm{l}$ of sample was incubated with saturating concentrations of FITCanti-GPIb (SZ2, AMAC) for 20 minutes, washed, and resuspended in $300 \mu$ l Tyrode's-HEPES buffer for fluorescence-activated cell sorter (FACS) analysis. ${ }^{4}$ To measure the percentage of circulating platelets expressing P-selectin, a separate $100 \mu \mathrm{l}$ of sample was incubated with fluorescein isothiocyanate (FITC)-anti-GPIIb/IIIa (P2, AMAC) and biotinylated-anti$\mathrm{P}$-selectin (1E3) MoAb for 20 minutes, washed, and resuspended in $100 \mu \mathrm{l}$ Tyrode's-HEPES buffer. The sample was then incubated with saturating concentrations of PE-avidin (BectonDickinson) for 20 minutes, washed, and resuspended in $300 \mu \mathrm{l}$ Tyrode's-HEPES buffer for FACS analysis. ${ }^{25}$

Leukocyte surface CD11 b was measured by incubating 100 $\mu$ l samples with saturating concentrations of PE-anti-CD1lb (D12, Becton-Dickinson) for 20 minutes. The samples were then washed and resuspended in $300 \mu$ l Tyrode's-HEPES buffer for FACS analysis. For the percentage of leukocyte-platelet conjugates, a separate $100 \mu \mathrm{l}$ sample was incubated with saturating concentrations of FITC-conjugated anti-CD45 and biotinylated anti-GPIIb/IIIa (P2, AMAC) MoAb for 20 minutes, then washed and resuspended in $100 \mu \mathrm{l}$ Tyrode's-HEPES buffer. PE-avidin labeling and preparation for FACS analysis were performed as previously stated.

Flow cytometry. Samples were analyzed on a FACScan flow cytometer (Becton-Dickinson) with data stored in list mode files. The determination of the surface density of GPIb and the percentage of platelets expressing P-selectin was done as previously described..$^{3,26,27}$ For GPIb, a single platelet gate using forward scatter was used to ensure that measurements of GPIb were not biased by microaggregate formation. The measurement of leukocyte surface CD11 b was done by live-gating on leukocyte-sized events, using forward- versus side-scatter parameters, with distinction of PMN versus monocytes by the same criteria. Analysis for conjugates has been previously described. ${ }^{12}$ As noted, isotype- and fluorochrome-matched control MoAB were used in each experiment to determine "nonspecific" background MoAB binding. Statistical analysis included repeated-measures analysis of variance and, where appropriate, an unpaired $t$ test.

\section{Results}

The demographics of the cyanotic and noncyanotic patients are shown in Table I. The two groups differed 


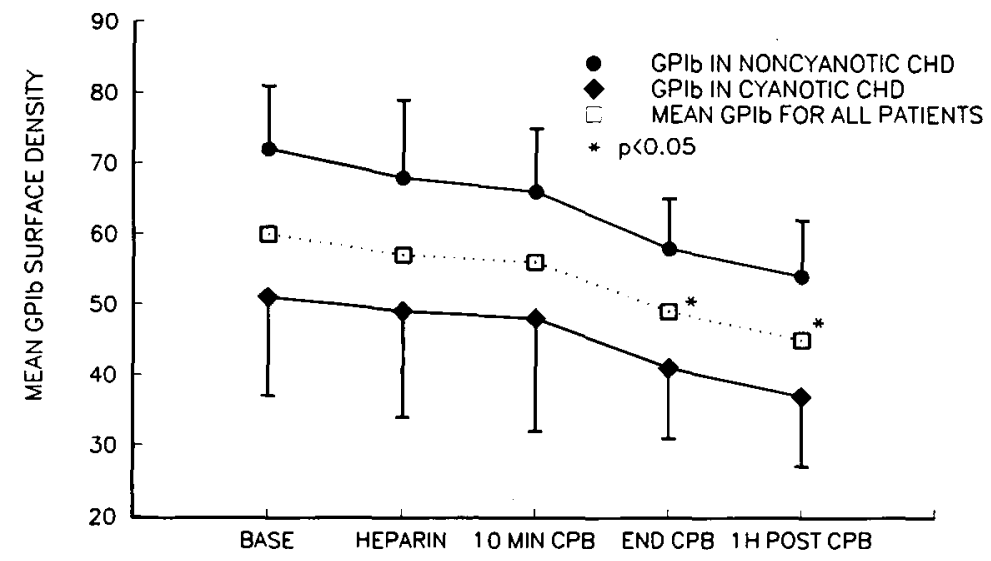

Fig. 1. Changes in surface expression of platelet GPIb. Mean fluorescence of anti-GPIb antibody binding to platelets was measured in samples of whole blood taken before start of operation $(B A S E), 5$ minutes after heparinization (HEPARIN), 10 minutes after start of operation (10 MIN CPB), shortly before separation from CPB (END CPB), and 1 to 2 hours after termination of CPB (IH POST CPB). Values are shown as mean \pm 1 standard deviation. Noncyanotic patients are represented by black circles, cyanotic patients by black diamonds, and mean for all patients by open squares. GBIb decreased significantly at end of CPB and 1 to 2 hours after CPB compared with baseline values. In addition, surface expression of GPIb in cyanotic patients was significantly lower than that in noncyanotic patients $(p=0.01)$ for all time points.

Table I. Demographics of the cyanotic and noncyanotic patients

\begin{tabular}{|c|c|c|}
\hline & $\begin{array}{c}\text { Cyanotic } \\
(\mathrm{n}=7)\end{array}$ & $\begin{array}{c}\text { Noncyanotic } \\
(\mathrm{n}=6)\end{array}$ \\
\hline Age (mo) & $15(0.2-36)$ & $14(0.4-60)$ \\
\hline Preop. hematocrit* & $46(38-53)$ & $38(33-41)$ \\
\hline CPB time $(\min )^{*}$ & $177(123-230)$ & $79(33-95)$ \\
\hline Weight (kg) & $8.1(4-13)$ & $9.9(6.5-59)$ \\
\hline 12-Hour blood loss/weight $\dagger$ & $26(7-43)$ & $15(8-89)$ \\
\hline RBCs transfused $(\mathrm{ml}) \ddagger$ & $56(0-170)$ & $32(0-70)$ \\
\hline Platelets transfused (ml) $\ddagger$ & $50(0-100)$ & $32(0-80)$ \\
\hline
\end{tabular}

Values are given as the mean and (in parenthesis) range. $R B C, \mathrm{Red}$ blood cells.

* Cyanotic group different from noncyanotic $(p<0.05)$.

†Chest tube drainage during 12 hours after operation/weight.

$\ddagger$ Milliliters transfused in first 24 hours after operation.

significantly in baseline hematocrit values and in the duration of $\mathrm{CPB}$, with the cyanotic patients having significantly longer CPB times. Other variables displayed did not differ significantly. Chest tube drainage adjusted for weight showed a trend toward being greater in the cyanotic patients, but the difference was not significant $(p=0.11)$. Cyanotic patients also received more platelet transfusions in the perioperative period (six of seven cyanotic patients versus one of six noncyanotic patients), but this did not reach statistical significance $(p=0.07)$. In the cyanotic group, operations included two atrioventricular canal repairs, both with pulmonary artery debanding and reconstruction; two fenestrated Fontan operations; an arterial switch with atrial septal defect closure; a tetralogy of Fallot repair; and a ventricular septal defect closure. In the noncyanotic group, three patients had patch closure of perimembranous ventricular septal defects, one including foramen ovale closure, and the other two also had primary closure of an atrial septal defect. One patient underwent a repeat aortic valvuloplasty, one a repeat transannular pulmonary artery patch (status after tetralogy of Fallot repair), and another a primary tetralogy of Fallot repair.

Platelet adhesion receptors. The average surface expression of the major platelet von Willebrand factor receptor, GPIb (Fig. 1), decreased during CPB, reaching significance at the end of $\mathrm{CPB}$ and decreasing further 1 to 2 hours after termination of CPB. The mean decrease in surface GPIb on single platelets fell to $75 \%$ of baseline values after $\mathrm{CPB}$, and in selected patients GPIb decreased to as low as $63 \%$ of baseline values. Comparison of cyanotic with noncyanotic patients revealed comparable percentage decreases in GPIb during the perioperative period, but as demonstrated in Fig. 1, the baseline density of GPIb in the cyanotic patients was lower than that in their noncyanotic counterparts and remained lower for all time points during and after $\mathrm{CPB}$. With the use of analysis of variance for repeated measurements, the difference between these patient groups was significant at $p=0.01$.

Platelet activation. The percentage of circulating activated platelets, that is, the percentage expressing sur- 


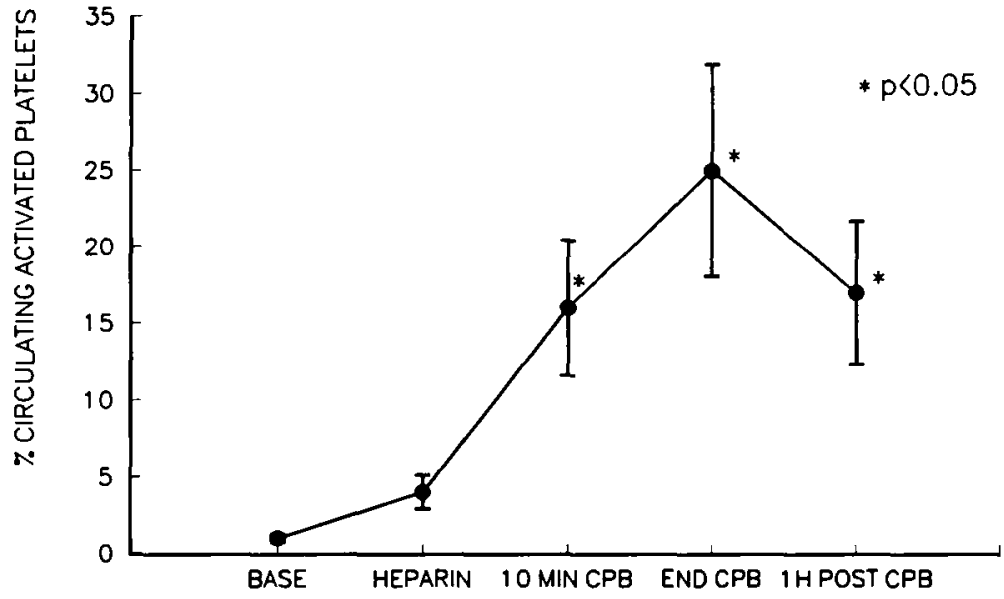

Fig. 2. Platelet activation with CPB. Percentage of circulating platelets expressing P-selectin was measured at time points described in Fig. 1. All values represent means \pm Standard error of the mean for the 13 patients.

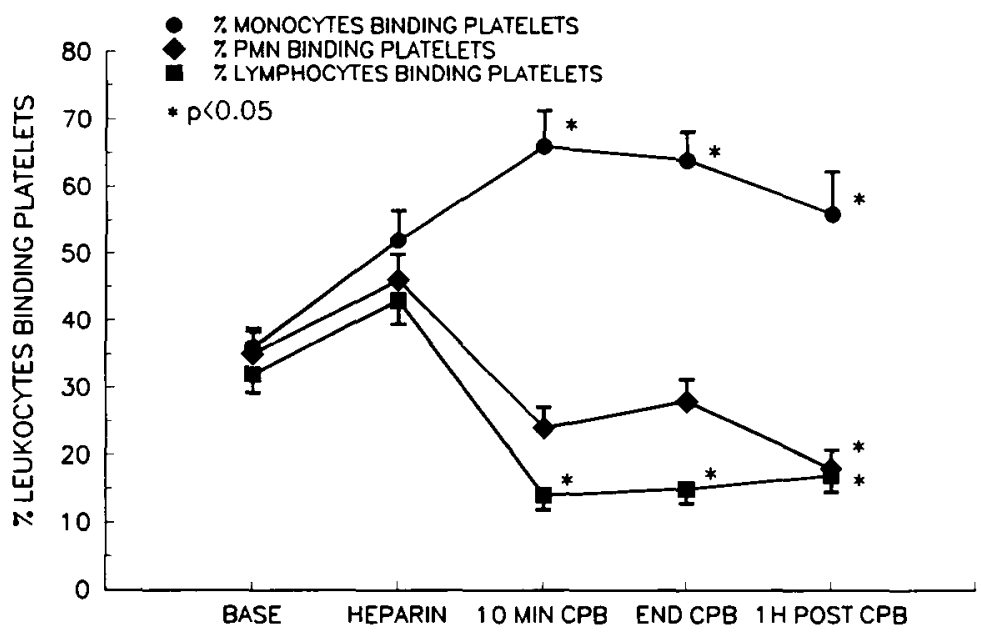

Fig. 3. Leukocyte-platelet conjugates with CPB. Percentage of leukocyte-platelet conjugates was measured in whole blood taken at time points described in Fig. 1. All values represent means \pm Standard error of the mean for the 13 patients.

face $P$-selectin, increased over baseline values within 10 minutes of the start of CPB (Fig. 2). This percentage continued to rise during CPB, peaking at $25 \% \pm 6.7 \%$ (mean \pm standard error of the mean for the 13 patients) of circulating platelets just before discontinuation of CPB. The percentage of $\mathrm{P}$-selectin-positive platelets at 1 to 2 hours after bypass then declined, but remained significantly higher than baseline levels. Comparison of the cyanotic and noncyanotic patients revealed no difference in either the time course or the degree of platelet activation occurring during CPB. The absolute platelet count decreased by $67 \%$ between the preoperative sample and that obtained 1 hour after CPB. The platelet counts in cyanotic and noncyanotic patients did not significantly differ at either time point.

Platelet-leukocyte binding. For the 13 patients, the percentage of leukocytes with bound platelets was comparable between leukocyte subsets before the start of operation, with $36 \% \pm 2.8 \%$ of monocytes and $35 \% \pm 2.8 \%$ of PMN binding platelets. The percentage of monocyte-platelet conjugates (Fig. 3) increased with the start of operation, then increased further at approximately 10 minutes after start of CPB with a mean of $66 \% \pm 5.3 \%$ of circulating monocytes having bound platelets $(p<0.05)$. This number remained essentially unchanged at the end of CPB and decreased slightly but 


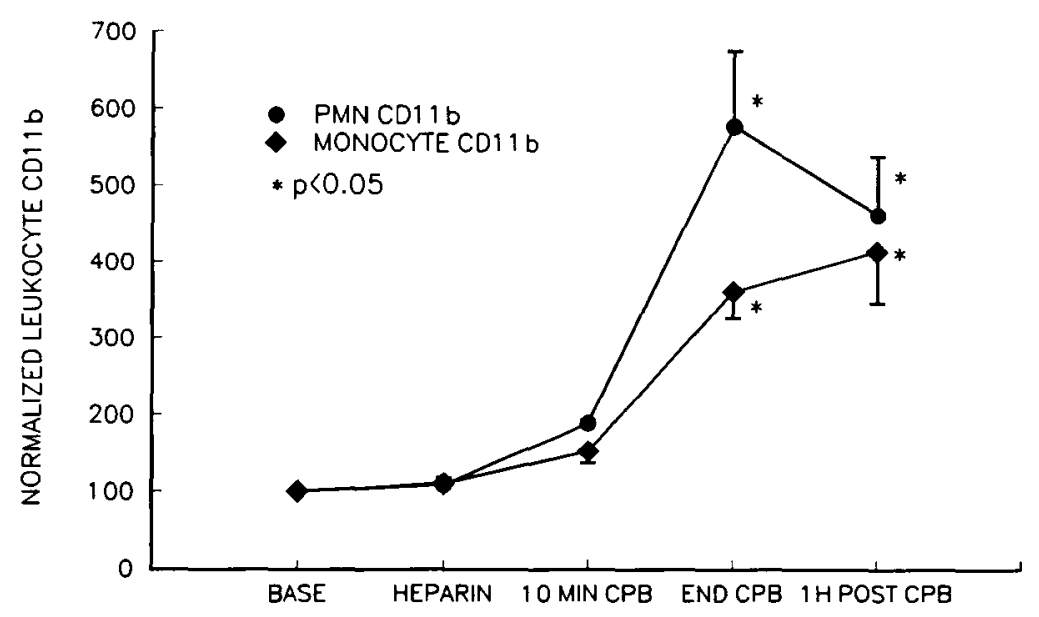

Fig. 4. Leukocyte CD11b with CPB. Fluorescence-labeling of CD1lb was measured on monocytes and PMN in whole blood taken at time points described in Fig. 1 and are expressed as percentage of baseline fluorescence value. Each measurement is shown as mean \pm standard error of the mean for the 13 patients.

remained significantly elevated over baseline binding at 1 to 2 hours after termination of CPB, where $56 \% \pm 6.4 \%$ of circulating monocytes had bound platelets.

The percentage of circulating PMN-platelet conjugates increased in the period before bypass, peaking at $46 \% \pm 4.4 \%$, markedly earlier and lower than peak monocyte-platelet binding. With initiation of $\mathrm{CPB}$, the percentage of $\mathrm{PMN}$-platelet conjugates declined, reaching significance at 1 to 2 hours after termination of CPB.

In a pattern similar to that of PMN-platelet binding, the percentage of circulating lymphocyte-platelet conjugates rose slightly in the period before bypass, then decreased significantly during CPB $(p<0.05)$, and remained significantly below baseline values at 1 to 2 hours after termination of CPB. There was no difference between cyanotic and noncyanotic patient groups in the numbers of circulating platelet-leukocyte conjugates at any time point.

Monocyte and PMN activation. Surface expression of CD11b on monocytes increased significantly ( $p<0.05$ ) during and after CPB, peaking 1 to 2 hours after termination of bypass (Fig. 4) at four times the baseline value. Expression of CD11b on PMN also increased significantly $(p<0.01)$ to a value five times that at baseline, but, unlike monocytes, PMN CDIlb peaked earlier than monocytes at termination of $\mathrm{CPB}$, then decreased in the early period after CPB. Cyanotic and noncyanotic patients demonstrated comparable increases in monocyte and PMN CD1lb.

The quantitative relationship between changes in platelet-leukocyte binding and simultaneous changes in leukocyte-CD1 lb expression over time for individual patients was examined to determine whether there was a temporal and quantitative correlation of monocyte and/ or PMN CD1 lb expression and increased circulating platelet-leukocyte conjugates. With the use of linear regression analysis, at the point of peak monocyte $C D 11 \mathrm{~b}$ expression (1 hour after CPB), the percentage of monocyte-platelet conjugates correlated with the monocyte CD1 1 b expression $(r=0.58, p=0.04)$. In contrast, there was an inverse relationship $(r=-0.49)$ between the degree of PMN-platelet adhesion and PMN CD11b expression, which was not statistically significant $(p=0.09)$. The absolute leukocyte count decreased by $29 \%$ over the course of CPB. The absolute number of PMNs rose by $25 \%$, whereas the number of monocytes and lymphocytes decreased by $79 \%$ and $67 \%$, respectively. Cyanotic and noncyanotic patients did not differ significantly with respect to these changes.

\section{Discussion}

Children with CHD undergoing operation necessitating CPB may represent a population at particular risk for hemorrhagic complications. The large volume of the bypass circuit relative to the patient's intravascular volume implies that circulating cells spend a majority of their time in contact with this foreign surface. In addition, children with $\mathrm{CHD}$, and in particular cyanotic $\mathrm{CHD}$, are likely to have preexisting platelet defects that result in a prolonged bleeding time ${ }^{15-19}$ and whose impact on perioperative bleeding has been difficult to ascertain. This is the first clinical study to examine alterations in platelet adhesion receptors in addition to activation of platelets and leukocytes in children undergoing $\mathrm{CPB}$ for cyanotic and noncyanotic CHD. In addition, this study has examined the changes in platelet-leukocyte conjugates during 
$\mathrm{CPB}$ and their relationship to platelet and leukocyte activation.

The platelet adhesion receptor, GPIb, is responsible for binding von Willebrand factor and is necessary for the initial adhesion of the platelet to damaged subendothelium under conditions of high shear stress. We and others have shown in adults that $\mathrm{CPB}$ results in a decrease in the surface expression of this adhesion receptor during $\mathrm{CPB}$ and continuing into the period after CPB. ${ }^{4,5}$ In this study we have shown that platelets in pediatric patients with CHD also demonstrate a decrease in GPIb during CPB, and the percentage decrease is comparable with that of the adult population. ${ }^{8}$ Comparison of cyanotic patients with their noncyanotic counterparts, however, revealed that at baseline and at every subsequent point, the surface expression of GPIb was lower in the cyanotic patients. This finding may explain the relatively high prevalence of a prolonged bleeding time in this population. Gil and associates ${ }^{28}$ have shown that patients with noncyanotic CHD have a high prevalence of a deficiency of the largest von Willebrand factor multimers, which are most hemostatically effective. This has not been studied in cyanotic patients; however, if true in cyanotic patients as well, this together with the baseline GPIb receptor deficit and the added decrease incurred during CPB may put these patients at particular risk for hemorrhagic complications. The cyanotic patients in this study exhibited a trend toward more blood loss and a higher requirement for platelet transfusions. A larger study is needed to determine if this difference is real and whether it can be attributed to the lower levels of GPIb in this population, the longer $\mathrm{CPB}$ times, or some combination of these and other variables.

In addition to serving as a marker for platelet $\alpha$-granule release, $\mathrm{P}$-selectin has been demonstrated to mediate in vitro binding of activated platelets to monocytes and PMN. ${ }^{9,29} \mathrm{We}$ and other investigators have previously demonstrated in adults that extracorporeal circulation activates platelets and causes an increase in the percentage of circulating platelets expressing P-selectin. This increase correlates with an increase in the percentage of monocyte-platelet conjugates and, to a lesser extent, PMN-platelet conjugates, ${ }^{8}$ reflecting the higher affinity of monocytes for activated platelets seen in vitro. ${ }^{12}$

In this study, unmanipulated blood drawn from an arterial catheter was immediately fixed in paraformaldehyde. Prior studies by our laboratory had shown that this procedure produces minimal $(<5 \%)$ activation of platelets and appears to provide a reasonable approximation of "in vivo" platelet-leukocyte conjugates. ${ }^{12}$ Although we cannot eliminate the possibility that the conjugate formation seen is an artifact of blood drawing or the stabil- ity of the assay over time, the dependence of activated platelet-leukocyte adhesion on both divalent cation and the G1 epitope of the P-selectin molecule in normal whole blood $9,12,28$ and the reproducible change observed over time in this study strongly suggest that these results reflect the in vivo situation.

There was a steady increase in both platelet activation and monocyte-platelet conjugate formation, the latter peaking 10 minutes after the start of $\mathrm{CPB}$ and remaining elevated during and 1 to 2 hours after CPB. PMN-platelet binding also rose in the period before bypass, then abruptly decreased with onset of CPB. The leukocyte receptor for P-selectin is not definitely known, ${ }^{10,30-33}$ but on PMN appears to be a labile one that decreases with PMN activation. ${ }^{34}$ The decrease in PMN-platelet adhesion with onset of $\mathrm{CPB}$ is consistent with the competitive advantage monocytes have over PMN, but may also reflect loss of the P-selectin receptor. The inverse relationship between PMN-platelet adhesion and PMN activation as measured by CD1 lb supports this latter explanation. Lymphocyte-platelet conjugates also decreased on bypass. This finding parallels in vitro observations that most lymphocytes do not bind P-selectinpositive platelets ${ }^{11}$ and, furthermore, that the platelet activation and subsequent adhesion to monocytes, along with the formation of platelet-platelet aggregation, can compete platelets off lymphocytes. ${ }^{12}$ This pattern of platelet activation and parallel formation of monocyteplatelet conjugates is comparable with that found in adults undergoing CPB. The percentage of activated platelets was slightly higher in this group of pediatric patients than in the adults ( $25 \%$ platelet activation versus $19 \%$ in adults), and the percentage of monocytes with bound platelets was significantly higher ( $66 \%$ of monocytes with bound platelets in the pediatric group versus $44 \%$ in adults, $p<0.05) .{ }^{8}$ These differences may reflect the increased blood volume exposed to the extracorporeal circuit relative to the intravascular volume in children or, possibly, the increased time on bypass. Alternatively, they may represent an intrinsic difference in pediatric versus adult platelets.

CD1 l b on monocytes and PMN increased over time on bypass, but with slightly different time courses. PMN expression of $\mathrm{CD} 11 \mathrm{~b}$ peaked at termination of $\mathrm{CPB}$ at five times its baseline values, whereas monocyte expression rose more gradually and peaked 1 to 2 hours after $\mathrm{CPB}$ at four times baseline values. As was seen in the adult population, monocyte $\mathrm{CD} 11 \mathrm{~b}$ expression correlated with monocyte-platelet conjugate formation, whereas PMN CD1 lb did not. The functions of CD1 $1 \mathrm{~b}$ are particularly relevant to CPB. CD11b is capable of binding $\mathrm{C} 3 \mathrm{~b}_{\mathrm{i}}$, fibrinogen, fibronectin, and factor $\mathrm{X} .{ }^{35}$ In animal 
models of reperfusion injury, infusion of anti-CD11b MoAB decreases PMN accumulation at the site of injured myocardium and increases tissue recovery. ${ }^{36}$ Furthermore, the addition of MoAb to monocytes in vitro results in marked interference with monocyte adherence to endothelial monolayers. ${ }^{37}$ Another factor that may contribute to tissue injury on CPB is classic and contact activation of the complement system. ${ }^{38} \mathrm{CD} 11 \mathrm{~b}$ may play a critical role in regulation of complement effects inasmuch as it functions as the receptor for the inactivated complement component $\mathrm{C} 3 \mathrm{~b}_{\mathrm{i}}{ }^{39}$

The complications that may occur after CPB include bleeding, ${ }^{40}$ pulmonary dysfunction, and other organ dysfunction. ${ }^{41}$ These may be due to a combination of cellular and soluble factor changes induced by CPB. One possible consequence of increased leukocyte-platelet adhesion is that such conjugates may be physically sequestered in the pulmonary or other localized vascular bed, producing local vasoactive changes, inflammation, or organ dysfunction. ${ }^{42}$ It is also possible that platelet adhesion to leukocytes induces leukocyte activation and subsequent elaboration of cytokines, ${ }^{43}$ which may cause pulmonary and systemic endothelial changes, leading to hypoxemia and tissue injury. Finally, platelet-leukocyte adhesion may result in enhanced monocyte procoagulant activity via increased tissue factor expression. ${ }^{14} \mathrm{We}$ believe it is unlikely that leukocyte-platelet conjugate formation contributes to the platelet defect associated with CPB. ${ }^{44}$ Because the activated platelets bind through $P$-selectin and therefore have undergone $\alpha$-granule release, their contribution to secondary aggregation is limited even if they remained free in the circulation.

$\mathrm{CD} 1 \mathrm{~b}$ upregulation on monocytes could be a result of (1) direct mechanical activation of leukocytes by the CPB apparatus or exposure to nonphysiologic biomaterials, (2) complement activation, ${ }^{45}$ or (3) as an indirect consequence of platelet activation followed by leukocyte-platelet adhesion and subsequent leukocyte activation. Our in vitro data suggest that platelet adhesion to monocytes is one signal that can result in upregulation of monocyte $\mathrm{CD} 1 \mathrm{lb}$ expression in whole blood and in fractionated cell assays. The time course on CPB of CD1 1 b expression on monocytes is similar to that in the in vitro data, and the correlation between platelet-monocyte binding and monocyte $\mathrm{CD} 1 \mathrm{lb}$ expression on $\mathrm{CPB}$ in adults and now in the pediatric population supports the possibility of upregulation of $\mathrm{CD} 1 \mathrm{lb}$ as a result of platelet binding. The absolute platelet and monocyte counts were decreased in the early period after bypass, coincident with peak monocyte CD11b expression and elevated platelet activation and platelet-monocyte adhesion. It is possible that plate- let-monocyte conjugate formation and increased expression of CD11b on monocytes contributes to the egress of platelets and monocytes from the circulation, but this cannot be confirmed from the present study. By contrast, our in vitro data showed that PMN-platelet conjugate formation was not accompanied by increased PMN $\mathrm{CD} 11 \mathrm{~b}$ expression. However, on $\mathrm{CPB}$, the insult from extracorporeal circulation and complement activation may act directly to induce CD11b expression on PMN. We hypothesize that all three mechanisms are operative in $\mathrm{CPB}$, with direct effects of the apparatus and complement activation possibly more critical to the PMN.

In summary, the changes in platelet and leukocyte adhesion receptors and platelet-leukocyte conjugate formation induced by CPB are qualitatively similar in pediatric patients with $\mathrm{CHD}$ to those in adults undergoing CPB for coronary artery bypass grafting. Of note, however, the cyanotic subgroup may be at particular risk for bleeding as a result of the decrease in the von Willebrand factor receptor on platelets induced by CPB superimposed on a baseline deficit in this receptor. These studies help form a basis for future examination of the benefits of various prophylactic and therapeutic interventions to prevent hemorrhagic and inflammatory complications in this patient group.

\section{REFERENCES}

1. Geng JG, Bevilacqua MP, Moore KL, et al. Rapid neutrophil adhesion to activated endothelium mediated by GMP140. Nature 1990;343:757-60.

2. Berman CL, Yeo EL, Wencel-Drake JD, Furie BC, Ginsberg $\mathrm{MH}$, Furie B. A platelet alpha granule membrane protein that is associated with the plasma membrane after activation. J Clin Invest 1986;78:130-6.

3. Rinder CS, Bonnert J, Rinder HM, Mitchell J, Ault KA, Hillman RS. Platelet activation and aggregation during cardiopulmonary bypass. Anesthesiology 1991;74:388-93.

4. Rinder CS, Mathew JP, Rinder HM, Bonan J, Ault KA, Smith BR. Modulation of platelet surface adhesion receptors during cardiopulmonary bypass. Anesthesiology 1991; 75:563-70.

5. George JN, Pickett EB, Saucerman S, et al. Platelet surface glycoproteins: studies on resting and activated platelets and platelet microparticles in normal subjects and observations in patients during adult respiratory distress syndrome and cardiac surgery. J Clin Invest 1986;78:340-8.

6. Wenger RK, Lukasiewicz H, Mikuta BS, Niewiarowski S, Edmunds LH. Loss of platelet fibrinogen receptors during clinical cardiopulmonary bypass. J THORAC CARDIOvaSC SURG 1989;97:235-9.

7. Wachtfogel Y, Kucich U, Greenplate JK, et al. Human neutrophil degranulation during extracorporeal circulation. Blood 1987;69:324-30. 
8. Rinder CS, Bonan JL, Rinder HM, Mathew J, Hines R, Smith BR. Cardiopulmonary bypass induces leukocyteplatelet adhesion. Blood 1992;79:1201-5.

9. Hamburger SA, McEver RP. GMP-140 mediates adhesion of stimulated platelet to neutrophils. Blood 1990;75:550-5.

10. Moore KL, Varki A, McEver RP. GMP-140 binds to a glycoprotein receptor on human neutrophils: evidence for a lectin-like interaction. J Cell Biol 1991;112:491-5.

11. Rinder HM, Bonan J, Rinder CS, Ault KA, Smith BR. Activated and unactivated platelet adhesion to monocytes and neutrophils. Blood 1991;78:1760-9.

12. Rinder HM, Bonan J, Rinder CS, Ault KA, Smith BR. Dynamics of leukocyte-platelet adhesion in whole blood. Blood 1991;78:173-6.

13. Rinder HM, Bonan J, Rinder CS, Smith BR. Differences between leukocyte subsets with respect to adhesion in whole blood [Abstract]. Blood 1991;78(suppl):731.

14. Catlett R, Moore K, McEver RP, Morrissey JH. GMP-140 (CD62) induces tissue factor expression in monocytes [Abstract]. Blood 1991;78 (suppl):279.

15. Mairer HM, McCue CM, Caul J, Still WJS. Impairment in platelet aggregation in congenital heart disease. Blood 1972;40:207-16.

16. Ekert $\mathrm{H}$, Cowling S. Platelet release abnormality and reduced prothrombin levels in children with cyanotic congenital heart disease. Aust Pediatr J 1977;13:17-21.

17. Kern FK, Morana NJ, Sears JJ, Hickey PR. Coagulation defects in neonates during cardiopulmonary bypass. Ann Thorac Surg 1992;54:541-6.

18. Suarez CR, Menendez CE, Griffin AJ, Ow EP, Walenga JM, Fareed J. Cyanotic congenital heart disease in children: hemostatic disorders and relevance of molecular markers of hemostasis. Semin Thromb Hemost 1984;10:285-9.

19. Ekert H, Sheers M. Preoperative and postoperative platelet function in cyanotic congenital heart disease. J THORAC CARDIOVASC SURG 1974;67:184-90.

20. Carmody M, Ault KA, Mitchell JG, Rote NS, Ng A. Production of monoclonal antibodies specific for platelet activation antigens and their use in evaluating platelet function. Hybridoma 1990;9:631-5.

21. McGregor JL, Brochier J, Wild F, et al. Monoclonal antibodies against platelet membrane glycoproteins. Eur J Biochem 1983;131:427-30.

22. Ruan C, Du X, Xi X, Castaldi PA, Berndt MC. A murine glycoprotein Ib complex monoclonal antibody SZ2 inhibits platelet aggregation induced by ristocetin and collagen. Blood 1987;69:570-4.

23. Beverley PCL. Production and use of monoclonal antibodies in transplantation immunology. In: Touraine JL, Trager J, Betuel J, et al., eds. Transplantation and clinical immunology XI. Amsterdam: Excerpta Medica, 1980:8793.

24. Ross GD, Cain JA, Lachmann PJ. Membrane complement receptor type three $\left(\mathrm{CR}_{3}\right)$ has lectin-like properties analogous to bovine conglutinin and functions as a receptor for zymosan and rabbit erythrocytes as well as a receptor for iC3b. J Immunol 1985;134:3307-11.

25. Ault KA, Rinder HM, Mitchell JG, Rinder CS, Lambrew CT, Hillman RS. Correlated measurement of platelet release and aggregation in whole blood. Cytometry 1989;10:448-55.

26. Shattil SJ, Cunninham M, Hoxie JA. Detection of activated platelets in whole blood using activation-dependent monoclonal antibodies and flow cytometry. Blood 1987; 70:307-17.

27. Rinder HM, Murphy M, Mitchell JG, Stocks J, Ault KA, Hillman RS. Progressive platelet activation with storage: evidence for shortened survival of activated platelets after transfusion. Transfusion 1991;31:409-14.

28. Gil JC, Wilson AD, Endres-Brooks J, Montgomery RR. Loss of the largest von Willebrand factor multimers from the plasma of patients with congenital cardiac defects. Blood 1986;67:758-61.

29. Larsen E, Celi A, Gilbert GE, et al. PADGEM protein: a receptor that mediates the interaction of activated platelets with neutrophils and monocytes. Cell 1989;59:305-10.

30. Corral L, Singer MS, Macher BA, Rosen SD. Requirement for sialic acid on neutrophils in a GMP-140 (PADGEM) mediated adhesive interaction with activated platelets. Biochem Biophys Res Commun 1990;172:1349-53.

31. Zhou Q, Moore KL, Smith DF, Varki A, McEver RP, Cummings RD. The selectin GMP-140 binds to sialylated, fucosylated lactosaminoglycans on both myeloid and nonmyeloid cells. J Cell Biol 1991;115:557-64.

32. Polley MJ, Phillips ML, Wayner E, et al. CD62 and endothelial cell-leukocyte adhesion molecule 1 (ELAM-1) recognize the same carbohydrate ligand, sialyl-Lewis $\mathrm{x}$. Proc Natl Acad Sci U S A 1991;88:6224-8.

33. Larsen GR, Sako D, Ahern TJ, Shaffer M. P-selectin and E-selectin: distinct but overlapping leukocyte ligand specificities. J Biol Chem 1992;267:11104-10.

34. Picker LJ, Warnock RA, Burns AR, Doerschuk CM, Berg EL, Butcher EC. The neutrophil selectin LECAM-1 presents carbohydrate ligands to the vascular selectins ELAM-1 and GMP-140. Cell 1991;66:921-33.

35. Albelda SM, Buck CA. Integrins and other cell adhesion molecules. FASEB J 1990;4:2868-80.

36. Simpson PJ, Todd RF III, Fantone JC, Michelson JK, Griffin JD, Lucchesi BR. Reduction of experimental canine myocardial reperfusion injury by a monoclonal antibody (antiMol, anti-CD11b) that inhibits leukocyte adhesion. J Clin Invest 1988;81:624-8.

37. Wallis WJ, Beatty PG, Ochs HD, Harlan JM. Human monocyte adherence to cultured vascular endothelium: monoclonal antibody-defined mechanisms. J Immunol 1985;135:2323-9.

38. Wachtfogel YT, Harpel PC, Edmunds LH Jr, Colman $\mathrm{RW}$. Formation of $\mathrm{Cl}_{\mathrm{s}} \mathrm{Cl}$-inhibitor, kallikrein-Cl-inhibitor, and plasmin- $\alpha_{2}$-plasmin inhibitor complexes during cardiopulmonary bypass. Blood 1989;73:468-74. 
39. Arnaout MA. Structure and function of the leukocyte adhesion molecules CD11/CD18. Blood 1990;75:1037-50.

40. Woodman RC, Harker LA. Bleeding complications associated with cardiopulmonary bypass. Blood 1990;76:168097.

41. Kirklin JK, Westaby S, Blackstone EH, Kirklin JW, Chenoweth DE, Pacifico AD. Complement and the damaging effects of cardiopulmonary bypass. J THORAC CARDIOVASC SURG 1983;86:845-51.

42. Braude S, Nolop K, Fleming J, Krausz T, Taylor K, Royston $\mathrm{D}$. Increased pulmonary transvascular protein flux after canine cardiopulmonary bypass: association with lung neutrophil sequestration and tissue peroxidation. Am Rev Respir Dis 1986;123:867-71.
43. Schleef RR, Bevilacqua MP, Sawdey M, Gimbrone MA Jr, Loskutoff DJ. Cytokine activation of vascular endothelium: effects on tissue-type plasminogen activator and type 1 plasminogen activator inhibitor. J Biol Chem 1988; 263:5797-803.

44. Harker LA, Malpass TW, Branson HE, Hessel EA, Slichter SJ. Mechanism of abnormal bleeding in patients undergoing cardiopulmonary bypass: acquired transient platelet dysfunction associated with selective $\alpha$-granule release. Blood 1980;56:824-30.

45. Salama A, Hugo F, Heinrich D, et al. Deposition of terminal C5b-9 complement complexes on erythrocytes and leukocytes during cardiopulmonary bypass. N Engl J Med 1988;318:408-12. 